\title{
The Takotsubo cardiomyopathy caused by the family drama
}

\author{
Mehmed Kulić ${ }^{1}$, Elnur Tahirović ${ }^{2 *}$ \\ Cardiology clinic ${ }^{1}$, Cardiosurgery clinic $^{2}$, University Clinical Center Sarajevo, Sarajevo, Bosnia and Herzegovina
}
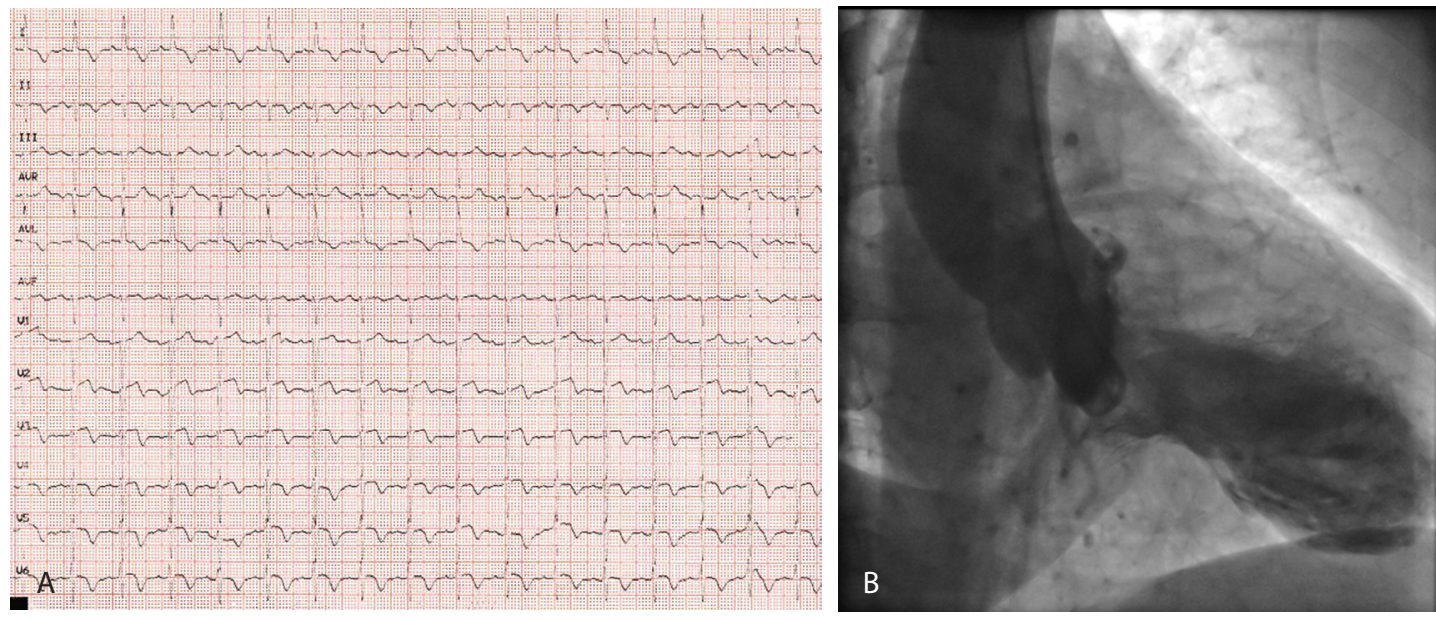

A 61 year old woman was admitted to our hospital for acute anginal pain which had occurred two hours before she was admitted. The symptoms started after she experienced psychological stress, due to her daughter's divorce. Her personal anamnesis was negative for coronary artery disease. An electrocardiogram (ECG) showed sinus rhythm with ST-segment elevation of $2 \mathrm{~mm}$ in leads V2-V3 and negative T waves in leads DI, DII, AVL, and V2-V6 (Panel A). Her troponin I level was $1196 \mathrm{pg} / \mathrm{ml}$ (normal range $<30 \mathrm{pg}$ / $\mathrm{ml})$. A transthoracic echocardiogram estimated the left ventricular ejection fraction at $35 \%$, with evidence of segmental motion abnormalities in the medioapical segments of the anterior, septal, inferior wall, with moderate mitral regurgitation. Coronary angiography was performed and we found normal coronary arteries, with left ventricular apical ballooning and hypercontraction of the basal segment (Panel B; (http://ama. ba/index.php/ama/article/view/264/264845-1-PC.HTML2). On the basis of these findings and anamnesis, Takotsubo cardiomyopathy or broken heart syndrome (1) was diagnosed. She was treated with medical therapy (diuretics, beta blockers, anticoagulant therapy, ACE-inhibitors) and after one month her echocardiogram was without any abnormalities. Also, the ECG normalized without any sign of myocardial ischemia. Although it has unclear pathogenesis, studies have shown that this cardiomyopathy is associated with a large quantity of catecholamines produced as a response to stress (2). 
Therefore, it is very important for physicians to recognize this very rare and frequently unrecognized cardiomyopathy, which can often mimic acute coronary syndrome.

Key words: Takotsubo cardiomyopathy - Acute coronary syndrome.

Authors' contributions: Conception and design: MK and ET; Acquisition, analysis and interpretation of data: ET and MK; Drafting the article: ET and MK; Revising it critically for important intellectual content: MK and ET; Approved final version of the manuscript: ET and MK.

Conflict of interest: The authors declare that they have no conflict of interest.

\author{
${ }^{*}$ Corresponding author \\ elnur.tahirovic@gmail.com \\ Tel.: + 38733298219 \\ Fax.: + 38733268791
}

Received: 15 February 2016; Accepted: 17 March 2016

\section{References}

1. Virani SS, Khan AN, Mendoza CE, Ferreira AC, de Marchena E. Takotsubo Cardiomyopathy, or Broken-Heart Syndrome. Tex Heart Inst J. 2007;34(1):76-9.

2. Komamura K, Fukui M, Iwasaku T, Hirotani S, Masuyama T. Takotsubo cardiomyopathy: Pathophysiology, diagnosis and treatment. World J Cardiol. 2014;6(7):602-9. 